\title{
Sorofrequência de infecção pelo vírus da imunodeficiência felina e vírus da leucemia felina em gatos do município de Araçatuba, São Paulo
}

\author{
Serofrequency of feline immunodeficiency virus and feline leukemia virus in cats of \\ Araçatuba, São Paulo
}
Ludmila Silva Vicente SOBRINHO ${ }^{1}$; Juliana Peloi VIDES ${ }^{1}$; Eveline Tozzi BRAGA ${ }^{1}$; Ana Amélia Domingues GOMES ${ }^{2}$; Claudio Nazaretian ROSSI ${ }^{3}$; Mary MARCONDES ${ }^{1}$

\author{
${ }^{1}$ Faculdade de Medicina Veterinária da Universidade Estadual Paulista, Araçatuba - SP, Brasil \\ ${ }^{2}$ Universidade Federal do Vale do São Francisco, Petrolina - PE, Brasil \\ ${ }^{3}$ Faculdade de Medicina Veterinária e Zootecnia da Universidade de São Paulo, São Paulo-SP, Brasil
}

\begin{abstract}
Resumo
A imunodeficiência viral felina e a leucemia viral felina representam importantes doenças infecciosas causadas por retrovírus. O presente estudo teve por objetivos investigar a sorofrequência da infecção pelo vírus da imunodeficiência felina (FIV) e pelo vírus da leucemia felina (FeLV) em gatos provenientes do município de Araçatuba, Estado de São Paulo. Amostras de sangue de 302 gatos foram colhidas e testadas quanto à presença de anticorpos antivírus da imunodeficiência felina e do antígeno do vírus da leucemia felina por meio do ELISA Snap-Combo FIV-FeLV (IDEXX Laboratories). A frequência de positividade para FIV foi de 5,63\% (17/302) e para FeLV de 0,33\% (1/302). Dos 17 gatos infectados pelo FIV, nove $(52,94 \%)$ eram sintomáticos. Houve um predomínio da infecção pelo FIV em machos $(p=$ $0,0316)$ e em gatos com idade variando entre um e três anos $(p=0,0324)$.
\end{abstract}

Palavras-chave: Felino. Imunossupressão. Retrovírus. Sorologia.

\begin{abstract}
Feline immunodeficiency virus and feline leukemia represent important infectious diseases caused by retroviruses. This study aimed to investigate the prevalence of infection by feline immunodeficiency virus (FIV) and feline leukemia virus (FeLV) in cats from the municipality of Araçatuba, São Paulo. Blood samples from 302 cats were collected and tested for the presence of antibodies against feline immunodeficiency virus and antigen of feline leukemia virus by ELISA ${ }^{\circledR}$ SnapCombo FIV-FeLV (IDEXX Laboratories). The frequency of FIV positivity was 5.63\% (17/302) and of FeLV was $0.33 \%$ $(1 / 302)$. Of the 17 cats infected with FIV, nine (52.94\%) were symptomatic. There was a prevalence of FIV infection in males $(p=0.0316)$ and cats aged between one and three years $(p=0.0324)$.
\end{abstract}

Keywords: Feline. Immunosuppression. Retrovirus. Serology.

\section{Introdução}

A imunodeficiência viral felina (FIV) e a leucemia viral felina (FeLV) representam importantes doenças infecciosas de gatos. Ambas são causadas por vírus da família Retroviridae e capazes de induzir uma perda progressiva de linfócitos CD4+ e CD8+, devido ao tropismo por linfócitos e macrófagos. Desta forma, podem permitir a ocorrência de infecções crônicas e recorrentes, causas significativas de morbidade e mortalidade nos felinos ${ }^{1,2}$. Ademais, a marca imunológica da infecção pelo FIV é a depleção de linfócitos TCD4+ que, por conseguinte, promove a redução da relação CD4+/CD8+ e disfunção das células B e T $\mathrm{T}^{3,4}$, à semelhança do que acontece nos indivíduos HIV-positivos 5 .

Os vírus da imunodeficiência felina (FIV) e o da imunodeficiência humana (HIV) são similares no que diz respeito às características biológicas e às disfun-

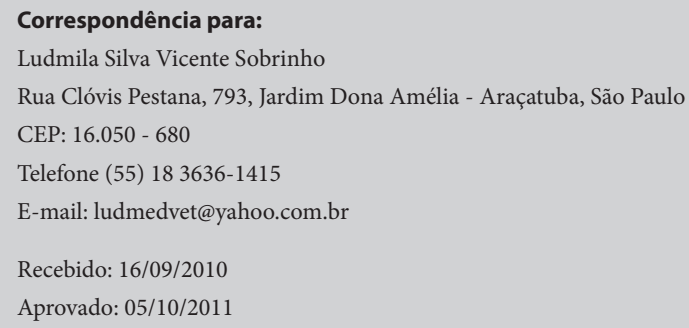


ções imunológicas que causam nos hospedeiros ${ }^{6}$. Neste contexto, a síndrome da imunodeficiência adquirida nos gatos domésticos tem ganhado um destaque especial na medicina veterinária, pois as semelhanças biológicas e morfológicas entre o FIV e o HIV propiciam estabelecer modelos experimentais para a infecção pelos Lentivírus, visando o estudo da patogenia e desenvolvimento de novos fármacos e vacinas ${ }^{7,8,9,10}$.

$\mathrm{O}$ vírus da imunodeficiência felina é eliminado em altas concentrações na saliva de gatos infectados, sendo o ato da mordedura o modo de transmissão mais eficaz ${ }^{11}$. Os sintomas inespecíficos em gatos infectados com o FIV incluem linfoadenopatia, mucosas pálidas, gengivite/estomatite, perda de peso, alterações nos sistemas digestório, tegumentar, oftálmico e nervoso ${ }^{11,12,13,14}$.

$\mathrm{O}$ vírus da leucemia felina (FeLV) é um retrovírus oncogênico e imunossupressor do gênero Gammaretrovírus ${ }^{1,15}$. Os felinos persistentemente infectados eliminam partículas virais em menor quantidade nas secreções respiratórias, lágrima, fezes, urina, sêmen e leite. Todavia, a via de transmissão efetiva ocorre na saliva, através do grooming e compartilhamento de recipientes de água e/ou alimento ${ }^{1}$. O vírus induz várias doenças proliferativas, como linfomas e leucemias, e muitas enfermidades degenerativas associadas às propriedades imunossupressoras do vírus ${ }^{16}$. Os sinais clínicos são inespecíficos e variam dependendo do tipo de doença e dos órgãos envolvidos, podendo incluir, anorexia, perda de peso, linfoadenopatia, febre, mucosas pálidas, gengivite, estomatite, uveíte, dispneia, enterites e abscessos que não cicatrizam ${ }^{15,17,18}$.

A condição epidemiológica mundial do FIV e do FeLV determinam taxas de prevalência variando de $1 \%$ a $44 \%$ e de $1 \%$ a $38 \%$ em populações de gatos de várias partes do mundo, respectivamente ${ }^{19,20,21}$.

Os métodos atuais para detectar a infecção por retrovírus de gato incluem o direto, como a reação em cadeia da polimerase (PCR), e o indireto por meio de técnicas imunológicas para detecção de anticorpos específicos como o ELISA, imunocromatografia e o Western blot ${ }^{22}$.

A característica imunossupressora e debilitante causada pela infecção de ambos os retrovírus, bem como as manifestações clínicas inespecíficas e facilidade de transmissão tornam o diagnóstico dessas enfermidades fundamental na clínica de felinos, não se restringindo apenas aos animais de reprodução ou portadores de neoplasias. Neste contexto, este estudo tem como objetivo verificar a sorofrequência das retroviroses de gatos provenientes do município de Araçatuba, Estado de São Paulo.

\section{Material e Método}

\section{Animais}

A presente pesquisa foi realizada com 302 felinos (escolhidos por conveniência), independentes de raça ou sexo, sintomáticos ou não, com faixa etária a partir de seis meses de idade (estimada pela análise da arcada dentária), encaminhados ao Centro de Controle de Zoonoses (CCZ) do município de Araçatuba, Estado de São Paulo (200 animais) ou provenientes de duas residências (102 animais), localizadas em bairros de classe social baixa do mesmo município, que funcionavam com abrigo.

\section{Detecção de anticorpos anti-FIV e de antígenos do $\mathrm{FeLV}$}

A presença de anticorpos antivírus da imunodeficiência felina e do antígeno do vírus da leucemia felina foram realizadas por meio do comercial assay Kit SNAP ${ }^{\oplus}$ FIV Antibody/FeLV Antigen Combo Test (IDEXX Laboratories Inc., EUA) que detecta o antígeno p27 do vírus da leucemia felina e anticorpos para o vírus da imunodeficiência felina. A metodologia e a interpretação dos resultados seguiu a recomendação do fabricante.

O experimento foi delineado de acordo com os Princípios Éticos na Experimentação Animal (COBEA) e aprovado pela Comissão de Ética na Experi- 
mentação Animal (CEEA), da Universidade Estadual Paulista "Júlio de Mesquita Filho" - UNESP - Campus de Araçatuba, conforme o protocolo no 2008-005699.

Os resultados obtidos foram submetidos à análise estatística através dos testes não paramétricos de Qui-quadrado e Fisher para verificar a associação entre as variáveis, sexo, faixa etária, definição racial e condição clínica.

\section{Resultados}

\section{População estudada}

A amostragem de 302 gatos foi composta por 152 (50,33\%) fêmeas e 150 (49,67\%) machos, 287 (95,03\%) animais sem raça definida e 15 (4,97\%) gatos da raça siamesa. Os animais entre seis meses e um ano de idade compreendiam 41,39\% (125 gatos) da população estudada, $34,77 \%$ (105/302) possuíam entre um e três anos, $15,90 \%(48 / 302)$ de três a cinco anos e 7,95\% (24/302) tinham idade superior a cinco anos. No que concerne à condição clínica dos felinos estudados, 65,56\% (198/302) dos animais eram clinicamente sadios, enquanto $34,44 \%(104 / 302)$ apresentavam sintomas inespecíficos compatíveis com a infecção por FIV/FeLV no exame físico geral.

\section{População infectada pelo FIV e o FeLV}

Dos 302 gatos testados, 17 (5,63\%) apresentaram anticorpos ant-vírus da imunodeficiência felina e apenas uma fêmea $(0,33 \%)$ apresentava somente antígenos do vírus da leucemia felina. Este animal possuía idade superior a cinco anos e apresentava hepatoesplenomegalia, perda do tônus muscular dos membros pélvicos e da cauda. Dos 17 gatos soro reagentes para o FIV, 11 eram oriundos do CCZ e seis de abrigos, nove $(52,94 \%)$ eram sintomáticos, com alterações clínicas variando desde distúrbios dermatológicos, observados em todos os animais, até hipertrofia de linfonodos poplíteos e submandibulares (encontrada em três gatos), desidratação, emagrecimento (verificado em outros dois gatos), conjunti- vite e hepatoesplenomegalia, sendo os dois últimos identificados em um único animal.

Verificou-se uma maior frequência da positividade para FIV em machos $(64,70 \%)$ em relação às fêmeas $(p=0,0316)$ e em gatos com faixa etária entre um e três anos de idade $(p=0,0324)$. Dos 11 gatos machos positivos para FIV, um tinha entre seis meses e um ano de idade, quatro gatos tinham entre um e três anos, três gatos tinham entre três e cincos anos e três apresentavam idade superior a cinco anos. Já com relação às seis fêmeas positivas para FIV, duas gatas tinham entre seis meses e um ano de idade, duas tinham entre um e três anos, uma tinha entre três e cincos anos e outra possuía idade superior a cinco anos. Quanto à distribuição racial houve maior frequência em animais sem raça definida do que naqueles da raça siamês $(p=0,0281)$. Não foi observada diferença estatística significativa em relação à condição clínica dos animais infectados pelo vírus da imunodeficiência felina $(p=0,1645)$.

Os resultados gerais da amostragem populacional, bem como os gatos infectados pelo vírus da imunodeficiência felina estão dispostos na tabela 1 .

\section{Discussão}

O diagnóstico das retroviroses de felinos não pode se fundamentar exclusivamente nas alterações clínicas dos pacientes, devendo ser baseado na demonstração de anticorpos anti-FIV e de antígenos do FeLV no soro dos animais, uma vez que ocorre a persistência da infecção viral mesmo frente a uma resposta imunológica conveniente ${ }^{23}$. A presente pesquisa utilizou um teste na forma de ensaio de imunoadsorção enzimática, disponível em Kit comercial, que apresenta rapidez na execução e interpretação dos resultados, bem como sensibilidade e especificidade elevadas ${ }^{24}$.

Embora a população de felinos avaliada neste estudo seja constituída de animais com acesso a rua, 
Tabela 1 - Número e percentagem de gatos positivos para anticorpos contra o vírus da imunodeficiência felina (FIV), segundo o sexo, faixa etária, definição racial e condição clínica, em uma população de 302 animais do município de Araçatuba-SP

\begin{tabular}{rrrr}
\hline \multicolumn{1}{c}{ Variáveis } & $\begin{array}{c}\text { Amostragem } \\
\text { populacional }\end{array}$ & FIV & Análise estatística \\
\hline Sexo & $150(49,67 \%)$ & $11(64,7 \%)^{\mathrm{a}}$ & $p=0,0316$ \\
Macho & $152(50,33 \%)$ & $6(35,29 \%)$ & \\
\hline Faixa etária & & & \\
6 meses-1 ano & $125(41,39 \%)$ & $3(17,65 \%)$ & \\
$1-3$ anos & $105(34,77 \%)$ & $6(35,29 \%)^{\mathrm{a}}$ & \\
$3-5$ anos & $48(15,90 \%)$ & $4(23,53 \%)$ & \\
$>5$ anos & $24(7,95 \%)$ & $4(23,53 \%)$ & $p=0,0281$ \\
SRD & $287(95,03 \%)$ & $15(88,24 \%)^{\mathrm{a}}$ & \\
Siamês & $15(4,97 \%)$ & $2(11,76 \%)$ & $p=0,1645$ \\
Definição racial & & & \\
Sintomático & $104(34,44 \%)$ & $9(52,94 \%)$ & \\
Assintomático & $198(65,56 \%)$ & $8(43,06 \%)$ & \\
\hline
\end{tabular}

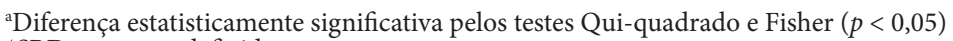

*SRD: sem raça definida

manejo nutricional precário e ausência de controle de enfermidades, a taxa de ocorrência de FIV (5,63\%) foi inferior à observada em um estudo conduzido com 454 gatos que viviam em residências e tinham livre acesso à rua, contudo, provenientes de 13 cidades do Estado de São Paulo ${ }^{25}$.

A percentagem de gatos positivos para o FIV encontrada foi inferior ao observado em outras partes do mundo, tais como na região noroeste do Mediterrâneo (6,5\%), na Espanha (7,9\%) e em Istambul $(22,3 \%)^{2,26,27}$. Contudo, a sorofrequência de 5,63\% do presente estudo foi superior à relatada em um estudo conduzido nos Estados Unidos, Canadá $(2,5 \%)$ e no município de Belo Horizonte $(4,14 \%)^{28,29}$.

Apesar de os gatos avaliados apresentarem procedência desconhecida e estarem em constante contato com gatos de vida errante, a taxa de infecção pelo FeLV $(0,33 \%)$ foi inferior ao relatado pela maioria dos autores que investigaram a presença de antígenos do retrovírus, com taxas de prevalência variando de 2,3\% a $38,3 \%$ em diversos países e $^{1,2,27,28,30,31,32,33}$.
Apesar de estudos pretéritos demonstrarem que a ocorrência de infecção por retrovírus felino pode ser influenciada pela caracterização da população analisada, sendo elevada principalmente em gatos que vivem em locais com alta densidade populacional e íntimo contato ${ }^{19}$, neste estudo não foi possível verificar uma expressão significativa destes fatores, e nem a associação entre as infecções pelo FIV e FeLV. Dos 17 gatos infectados pelo FIV, apenas seis eram provenientes de abrigos, sendo dois de um abrigo e quatro do outro. Os outros animais eram provenientes do Centro de Controle de Zoonoses do Município de Araçatuba-SP.

Aproximadamente metade $(52,94 \%)$ dos animais infectados pelo FIV apresentava alguma alteração clínica, como apatia, linfoadenomegalia, perda de peso, desidratação, hepatoesplenomegalia, secreção ocular bilateral purulenta e estomatite. Alguns gatos possuíam dermatopatias caracterizadas pela presença de áreas de alopecia, hiperqueratose, lignificação, hiperpigmentação e ulcerações cutâneas com depo- 
sição de crostas hemorrágicas e melicéricas. Embora muitos desses sintomas tenham sido também relatados por outros autores ${ }^{1,2}$, não é possível afirmar que sejam exclusivamente decorrentes de infecção por retrovírus, uma vez que a imunossupressão causada pelo mesmo permite o desenvolvimento de neoplasias e infecções oportunistas ${ }^{22}$.

O número de gatos soro reagentes e sintomáticos ao FIV foi estatisticamente semelhante à proporção de animais assintomáticos $(p=0,1645)$. Outros estudos associaram os sintomas à infecção pelo FIV. Por se tratarem de doenças de caráter imunossupressor, as manifestações clínicas de gatos infectados com FIV e FeLV são bem diversas e muitas vezes inespecíficas ${ }^{25,28,34}$.

Houve uma predisposição da infecção pelo FIV em machos $(p=0,0316)$, confirmando observações de outros autores ${ }^{2,25,28,32}$. De fato, o comportamento característico dos machos pode explicar sua maior suscetibilidade à infecção pelo retrovírus, haja vista que o modo de transmissão deste agente está relacionado aos hábitos inerentes da espécie, como disputas territoriais e procura de fêmeas para o acasalamento, permitindo maior contato entre os animais ${ }^{35}$.

A maioria dos gatos FIV-positivos possuía entre um e três anos de idade $(p=0,0324)$, similar ao obser-

\section{Referências}

1. ARJONA, A.; ESCOLAR, E.; SOTO, I.; BARQUERO, N.; MARTIN, D.; LUCIA, E. G. Seropidemiological survey of infection by leukemia virus and immunodeficiency vírus in Madrid and correlation with some clinical aspects. Journal of Clinical Microbiology, v. 38, n. 1, p. 3448-3449, 2000.

2. YILMAZ, H.; ILGAZ, A.; HARBOUR, D. A. Prevalence of FIV and FeLV infections in cats in Istanbul. Journal of Feline Medicine and Surgery, v. 2, n. 1, p. 69-70, 2000.

3. ACKLEY, C. D.; YAMAMOTO, J. K.; LEVY, N. B.; PEDERSEN, N. C.; COOPER, M. D. Immunologic abnormalities in pathogen-free cats experimentally infected with feline immunodeficiency virus. Journal of Virology, v. 64, n. 11, p. 5652-5655, 1990.

4. TANIGUCHI, A.; ISHIDA, T.; WASHIZU, T.; TOMODA, I. Humoral immune response to T-cell dependent and independent antigens in cats infected with feline vado em estudos conduzidos nos Estados Unidos, no Canadá e na Espanha ${ }^{1,28}$. Tal assertiva reforça a hipótese de que o comportamento reprodutivo parece ser uma variável importante e correlacionada ao modo de transmissão do vírus. Apesar de ter sido verificada uma predisposição da infecção em gatos sem raça definida ( $p=0,0281)$, a amostragem populacional também era composta quase que em sua totalidade $(95,03 \%)$ por animais sem definição racial.

Como a população de animais estudada era oriunda do Centro de Controle de Zoonoses e de duas residências que os acolhiam a real procedência e sanidade dos mesmos era desconhecida. Sob esta reflexão, esperava-se que esta amostragem populacional fosse mais suscetível ou tivesse maior predisposição em apresentar as infecções por retrovírus, haja vista o íntimo convívio entre os gatos.

Conclui-se que medidas profiláticas sobre as classes de gatos demonstradas como mais suscetíveis à infecção por FIV poderiam ser mais eficientes, especialmente, no que diz respeito ao estilo de vida livre e ao manejo destes animais.

\section{Agradecimentos}

À Fundação de Amparo à Pesquisa do Estado de São Paulo (FAPESP) pelo suporte financeiro do projeto no 2009/52333-8.

immunodeficiency virus. The Journal of Veterinary Medical Science, v. 53, n. 2, p. 333-335, 1991.

5. GEBHARD, D. H.; DOW, J. L.; CHILDERS, T. A.; ALVELO, J. I.; TOMPKINS, M. B.; TOMPKINS, W. A. F. Progressive expansion of an L-selectin-negative CD8 cell with anti-feline immunodeficiency virus (FIV) suppressor function in the circulation of FIV-infected cats. Journal of Infection Disease, v. 180, n. 5, p. 1503-1513, 1999.

6.DUA, N.; REUBEL, G.; MOORE, P. F. An experimental study of primary feline immunodeficiency virus infection in cats and a historical comparison to acute simian and human immunodeficiency virus diseases. Veterinary Immunology and Immunopathology, v. 43, n. 1, p. 337-335, 1994.

7. AVERY, P. R. Feline immunodeficiency vírus. In: LAPPIN, M. R. Feline internal medicine secrets, Philadelphia: Hanley \& Belfus, 2001. cap. 77, p. 391-397. 
8. BACHMANN, M. H.; MATUIASON-DUBARD, C.; LEARN, G. H.; RODRIGO, A. G.; SODORA, D. L.; MAZZETTI, P.; HOOVER, E. A.; MULLINS, J. I. Genetic diversity of feline immunodeficiency virus: dual infection, recombination, and distinct evolutionary rates among envelope sequence clades. Journal of Virology, v. 71, n. 6, p. 4241-4253, 1997.

9. FOOSHEE, S. K. Feline immunodeficiency virus infection. In: NORSWORTHY, G.D.; CRYSTAL, M.A.; FOOSHEE, S K.; TILLEY, L. P.; CRYSTAL, M. The feline patient: essentials of diagnosis and treatment. Baltimore: Lippincott Williams \& Wilkins, 1998. cap. 52, p. 193-196.

10. WILLETT, B. J.; FLYNN, J. N.; HOSIE, M. J. FIV infection of the domestic cat: an animal model for AIDS. Immunology Today, v. 18, n. 4, p. 182-189, 1997.

11.YAMAMOTO, J. K.; HANSEN, H.; HO, E. W.; MORISHITA, T. Y.; OKUDA, T.; SAWA, T. R.; NAKAMURA, R. M Epidemiologic and clinical aspects of feline immunodeficiency virus infection in cats from the continental United States and Canada and possible mode of transmission. Journal of the American Medical Association, v. 194, n. 2, p. 213-220, 1989.

12.BURKHARD, M. J.; HOOVER, E. A. Feline immunodeficiency virus (FIV): clinical manifestations and management. Feline Practice, v. 27, n. 1, p. 10-14, 1999.

13.SHELTON, G. H.; ABKOWITZ, J. L.; LINENBERGER, M. L.; RUSSELL, R. G.; GRANT, C. K. Chronic leukopenia associated with feline immunodeficiency virus infection in a cat. Journal of American Veterinary Medical Association, v. 194, n. 2, p. 253-255, 1990.

14.TEIXEIRA, C. H. R.; SOUZA, H. J. M. Manifestações clínicas associadas à infecção pelo vírus da imunodeficiência felina. In: SOUZA, H. J. M. Coletâneas em medicina e cirurgia felina. Rio de Janeiro: L. F. Livros, 2003. cap.25, p. 301-321.

15.SOUZA, H. J. M.; TEIXEIRA, C. H. R. Leucemia viral felina. In: SOUZA, H. J. M. Coletâneas em medicina e cirurgia felina. Rio de Janeiro: L. F. Livros, 2003. cap. 22, p. 251-271.

16.HAGIWARA, M. K.; RECHE JUNIOR, A.; LUCAS, S. R. R Estudo clínico de infecção pelo vírus da leucemia felina em São Paulo. Revista Brasileira de Ciência Veterinária, Niterói, v. 4, p. 35-38, 1997.

17.JARRET, O. Strategies of retrovirus survival in the cat. Veterinary Microbiology, v. 69, n. 1/2, p. 99-107, 1999.

18.LAPPIN, M. R. Feline leukemia virus. In: SEMINÁRIO INTERNACIONAL DE DOENCAS INFECCIOSAS, 1998, São Paulo. Anais... São Paulo, 1998. p. 36-44.

19.BRALEY, J. FeLV and FIV: survey shows prevalence in the United States and Europa. Feline Practice, v. 22, p. 25-28, 1994.

20. HOSIE, M. J.; ROBERTSON, C.; JARRET, O. Prevalence of feline leukaemia virus and antibodies to feline immunodeficiency virus in cats in United Kingdom. Veterinary Record, v. 128 , n. 11, p. 293-297, 1989.

21.ISHIDA, T.; WASHIZU, T.; TORIYABE, K.; MOTOYOSHI, S.; TOMODA, I.; PEDERSEN, N. C. Feline immunodeficiency virus infection cats of Japan. Journal of American Veterinary Medicine Association, v. 194, n. 2, p. 221-225, 1989.

22.HOSIE, M. J.; ADDIE, D.; BELAK, S.; BOUCRAUTBARALON, C.; EGBERINK, H.; FRYMUS, T.; GRUFFYDDJONES, T.; HARTMANN, K.; LLORET, A.; LUTZ, H.; MARSILIO, F.; PENNISI, M. G.; RADFORD, A. D.; THIRY, E.; TRUYEN, U.; HORZINEK, M. C. Feline immunodeficiency. ABCD guidelines on prevention and management. Journal of Feline Medicine and Surgery, v. 11, n. 7, p. 575-584, 2009

23. BENDINELLI, M.; PISTELLO, M.; LOMBARDI, S.; POLI, A.; GARZELLI, C.; MATTEUCCI, D.; CECCHERINI-NELLI,
L.; MALVALDI, G.; TOZZINI, F. Feline immunodeficiency virus: an interesting model for AIDS studies and a important cat pathogen. Clinical Microbiology Reviews, v. 8, n. 1, p. $87-$ 112,1995 .

24.CRAWFORD, P. C.; LEVY, J. K. New challenges for the diagnosis of feline immunodeficiency virus infection. Veterinary Clinics of North America: Small Animal Practice, v. 37, n. 2, p. 335-350, 2007.

25.LARA, V. M.; TANIWAKI, S. A.; ARAÚJO JÚNIOR, J. P. Occurrence of feline immunodeficiency virus infection in cats. Ciência Rural, Santa Maria, v. 38, n. 8, p. 2245-2249, 2008.

26. MARTÍN-SÁNCHEZ, J.; ACEDO, C.; MUÑOS-PÉREZ, M.; PESSON, B.; MARCHAL, O.; MORILLAS-MÁRQUEZ，F Infection by Leishmania infantum in cats: epidemiological study in Spain. Veterinary Parasitology, v. 30, n. 145, p. 267 273, 2007.

27.SOLANO-GALLEGO, L.; RODRÍGUEZ-CORTÉS, A.; INIESTA, L.; QUINTANA, J.; PASTOR, J.; ESPADA, Y.; PÓRTUS, M.; ALBEROLA, J. Cross-sectional serosurvey of feline leishmaniasis in ecoregions around the Northwestern Mediterranean. American Journal of Tropical Medicine and Hygiene, v. 76, n. 4, p. 676-680, 2007.

28.LEVY, J. K.; SCOTT, H. M.; LACHTARA, J. L.; CRAWFORD, P. C. Seroprevalence of feline leukemia virus and feline immunodeficiency virus infection among cats in North America and risk factors for seropositivity. Journal of the American Veterinary Medical Association, v. 228, n. 3, p. 371-376, 2006.

29. TEIXEIRA, B. M.; RAJÃO, D. S.; HADDAD, J. A. P.; LEITE, R. C.; REIS, J. K. P. Ocorrência do vírus da imunodeficiência felina e vírus da leucemia felina em gatos domésticos mantidos em abrigos no município de Belo Horizonte. Arquivo Brasileiro de Medicina Veterinária e Zootecnia, v. 59, n. 4, p. 939-942, 2007.

30. COSTA, U. M.; REISCHAK, D.; SCHMITT, A. C.; RENCK, L.; OLIVEIRA, E. S.; FERREIRO, L. Detection of feline leukemia virus (FeLV) antigen from 1992 to june 2000 by indirect immunofluorescence test in Porto Alegre, Rio Grande do Sul, Brazil. Journal of the Brazilian Society for Virology, v. 5, n. 1, p. 94-95, 2000. Supplement.

31.DORNY, P.; SPEYBROECK, N.; VERSTRAETE, S.; BAEKE, M.; De BECKER, A.; BERKVENS, D.; VERCRUYSSE, J. Serological survey of Toxoplasma gondii, feline immunodeficiency virus and feline leukaemia virus in urban stray cats in Belgium. Veterinary Record, v. 151, n. 21, p. 626-629, 2002.

32. MEINERZ, A. R. M.; ANTUNES, T. A.; De SOUZA, L. L.; NASCENTE, P. S.; FARIA, R. O. de; CLEFF, M. B.; GOMES, F. R.; NOBRE, M. O.; REISCHAK, D.; SCHUCH, L. F. D.; MEIRELES, M. C.; ARAÚJO, M. C. Frequencia do vírus da leucemia felina (VLFe) em felinos domésticos (Felis catus) semidomiciliados nos municípios de Pelotas e Rio Grande. Ciência Animal Brasileira, v. 11, n. 1, p. 90-93, 2010.

33.SOUZA, H. J. M.; TEIXEIRA, C. H. R.; GRACA, R. F. S. Estudo epidemiológico de infecções pelo vírus da leucemia e/ou imunodeficiência felina, em gatos domésticos do Município do Rio de Janeiro. Clínica Veterinária, Curitiba, v. 7, n. 36, p. $14-21,2002$

34.DANIEL, A. G. T.; HAIPEK, K.; RECHE JR., A. Prevalence of infection by feline immunodeficiency virus (FIV) and/or feline leukemia virus (FeLV) in cats with chronic gingivitis. On Line Journal Veterinary Research, v. 10, n. 1, p. 42-54, 2006.

35.LUCAS, S. R. R.; HAGIWARA, M. K.; RECHE JR, A.; GERMANO, P. M. L. Ocorrência de anticorpos antitoxoplasma em gatos infectados naturalmente pelo vírus da imunodeficiência dos felinos. Brazilian Journal of Veterinary Research and Animal Science, v. 35, n. 1, p. 41-45, 1998. 